\title{
Dietary restriction and the development of atherosclerosis
}

\author{
BY M. T. RAVI SUBBIAH* AND R. G. SIEKERT JR \\ Lipid Research Center, University of Cincinnati Medical Center, Cincinnati, Ohio 45229, \\ USA and Mayo Clinic and Mayo Foundation, Rochester, Minnesota 55901, USA
}

(Received I 6 January 1978- Accepted I I April I978)

1. White Carneau pigeons develop genetic atherosclerosis. The aorta shows intimal cushions at birth, cholesterol accumulation at 9 months of age and definite atherosclerotic lesions by 3 years of age. To determine whether these age-related arterial changes can be prevented by dietary restriction started early in life, 3-month-old pigeons were subjected to dietary restriction ( $40 \%$ of ad lib. diet).

2. Plasma cholesterol levels, cholesterol excretion and aortic cholesterol concentrations were compared with those of pigeons on the ad lib. diet. The pigeons on dietary restriction showed a decrease of $30 \%$ in weight. The plasma cholesterol levels of these pigeons decreased $20 \%$ when compared with those of the ad lib. group. In the dietary-restricted group, both the faecal excretion of bile acids $(P<0.0 I)$ and the aortic cholesterol level $(P<0.02)$ were significantly reduced, with changes in the free and in the esterified sterol fraction.

3. This study shows, for the first time, that age-related accumulation of aortic cholesterol can be prevented or at least delayed by dietary restriction started early in life.

Atherosclerosis and its complications are the chief causes of death in the United States (National Heart \& Lung Institute Task Force on Arteriosclerosis, I971). Epidemiologic and pathologic studies have shown that the progression of this disease is age-related (Strong \& McGill, 1969; Haust, 1971). Fatty streaks in the aorta appear during the first two decades of life, fibrous plaques by the third decade and complicated lesions during the fourth and fifth decades. Consequently, there is much interest in determining whether dietary or medical intervention started early in life can prevent the age-related progression leading to complicated lesions.

Whether such an intervention programme can prevent naturally occurring disease has never been demonstrated in any animal model. Although some studies (Armstrong et al. 1970; Tucker et al. 1971) have shown that, in cholesterol feeding, atherosclerotic lesions can regress after the withdrawal of cholesterol, it is not known whether the steps involved in the progression of naturally occurring disease can be prevented or modified. This type of intervention study needs an animal model that (I) depicts a $100 \%$ incidence of the disease and (2) shows age-related arterial changes without cholesterol feeding or other endothelial injury leading to atherosclerosis.

Clarkson et al. (1959) described a $100 \%$ incidence of spontaneous atherosclerosis in the aortas of White Carneau pigeons. Studies from their laboratories as well as our laboratory (Lofland et al. 1965; Lauper et al. 1975; Subbiah et al. 1976) have shown that the aortas of these pigeons have (1) intimal cushions at birth, (2) cholesterol accumulation beginning at 9 months of age and (3) well-established atherosclerotic lesions by 3 years of age. This provides us with an ideal opportunity to determine whether this sequence of changes(especially the critical step of cholesterol accumulation which occurs at 9 months of age) can be prevented or delayed by early intervention.

We investigated the effect of dietary restriction started early in life ( 3 months of age) in the White Carneau pigeon on the plasma cholesterol level, cholesterol excretion, and aortic cholesterol accumulation after a 9-month period. We chose dietary restriction as the mode of intervention because earlier studies (Ross, 1972) have shown that the life-span of animals

* Reprint request: Dr M. T. R. Subbiah, K-4 Pavilion, Cincinnati General Hospital, 234 Goodman Street, Cincinnati, Ohio 45229. 
can be increased by restricting the energy intake in early life and that this effect may be accomplished through its beneficial effect on degenerative diseases like atherosclerosis.

\section{Methods \\ Experimental design}

White Carneau pigeons ( 3 months old) were obtained from the Palmetto Pigeon Plant, Sumter, South Carolina, and were given a cholesterol-free grain diet (Purina Pigeon Chow with $(\mathrm{g} / \mathrm{kg})$ I 50 protein, 30 fat and 60 crude fibre) throughout the experimental period. A group of thirty pigeons of mixed sexes was randomly assigned to a control or an experimental group. Pigeons do not show any sex differences in the incidence of atherosclerosis (Clarkson et al. 1959), unlike other species. The pigeons were kept in individual metabolism cages during the entire study ( 9 months). The dietary intake of the control group of pigeons (ad lib. group) was carefully monitored initially. The experimental group (dietary-restricted group) was then given $40 \%$ of the dietary intake of the $a d$ lib. group. The dietary intake of the control group was monitored weekly, and the intake of the dietary-restricted group was adjusted to $40 \%$ of that intake. However, the adjustment needed was found to be minimal because dietary intake of the ad lib. group did not change significantly during the 9-month period $(29 \cdot 2-35 \cdot 1 \mathrm{~g})$. Body-weights and plasma cholesterol levels were monitored regularly. The pigeons were killed 9 months after the study was begun (after the period of lipid accumulation). Cholesterol balance studies were done in a group of five pigeons before killing.

\section{Sterol excretion}

For the cholesterol excretion studies, pigeons were housed individually in screen-bottom cages (Subbiah \& Connelly, I976) specifically built to have water and food pans attached to the outside of the cages in positions that were accessible to the birds. The food pans were protected with partial covers to decrease spillage. Known amounts of food pellets were weighed into the pans each day, and the food intake was calculated from the weight of the pellets remaining the next day, after correcting for spillage.

The faecal samples were collected in a tray covered with plastic film (Saran Wrap) kept under the cages. The refrigerated faecal samples of individual birds for the entire I-week period were pooled and weighed. The food intake was calculated for the I-week period. The birds were weighed before and after the study. $\beta$-Sitosterol present in the diet was used as a non-absorbable marker to correct for variations in faecal flow and stool collection (Spittell et al. 1976). Its concentration in the diet was measured before the study.

The faecal neutral sterols were extracted and purified as described previously (Subbiah \& Connelly, 1976), based on the procedure of Miettinen et al. (1965). This procedure includes the homogenization of faecal samples, saponification of steryl esters, extraction of steroids with petroleum ether, separation by thin-layer chromatography and, finally, identification and quantitation by gas-liquid chromatography. Determinations were done in duplicate. Because pigeons do not excrete $5 \beta$-reduction products of cholesterol (Spittell et al. 1976) (coprostanol, coprostanone), there was only a single band on thin-layer chromatography corresponding to $\Delta^{5}$-sterols.

Neutral steroids were then eluted and quantitated as trimethylsilyl ether derivatives by

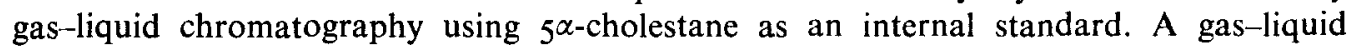
chromatograph containing 3.8\% W-98 (Model 409; Hewlett Packard, Avondale, Pennsylvania) was used for the sterol analysis. Conditions were: flash heater $300^{\circ}$, detector $270^{\circ}$, column $230^{\circ}$, and carrier gas, helium, $50 \mathrm{ml} / \mathrm{min}$. Losses of sterols during the chemical procedures were corrected on the basis of the recovery of $\left[{ }^{14} \mathrm{C}\right]$ cholesterol.

The faecal bile acids were analysed by a procedure described previously from this labora- 
Table 1. Body-weight, dietary intake and plasma lipid levels of White Carneau pigeons at the end of study period

(Mean values with their standard errors)

$\begin{array}{lclcc}\text { Group } \dagger & \begin{array}{c}\text { No. of } \\ \text { birds }\end{array} & \text { Body-wt (g) } & \begin{array}{c}\text { Average dietary } \\ \text { intake }(\mathrm{g})\end{array} & \begin{array}{c}\text { Plasma cholesterol } \\ \text { (mmol/l) }\end{array} \\ \text { Ad lib. } & \text { I5 } & 509 \pm 68 & 35 \cdot 1 \pm 3 \cdot \mathrm{I} & 6 \cdot 9 \pm \mathrm{I} \cdot \mathrm{I} \\ \text { Dietary restriction } & \text { I5 } & 360 \pm 66^{*} & \mathrm{I} \cdot 6 \pm 2 \cdot 3^{*} & 5 \cdot 5 \pm \mathrm{I} \cdot 2^{*}\end{array}$

Initial body-weights in control and dietary-restricted group were $583 \pm 26$ and $567 \pm 23 \mathrm{~g}$ respectively.

* Statistically different from ad lib. group $(P<0.01)$.

+ For details, see p. 2.

tory (Subbiah, 1973; Subbiah et al. 1976). The extracted bile acids were deconjugated by basic hydrolysis, methylated and then quantitated as trifluoroacetate ester derivatives by gas-liquid chromatography using hyocholic acid as an internal standard. A gas-liquid chromatograph (F \& M model 402; Applied Science, State College, Pennsylvania) with 3\% QF-I columns was used for this analysis. Conditions were: column $220^{\circ}$, flash heater $240^{\circ}$, detector $250^{\circ}$, and carrier gas, helium, $50 \mathrm{ml} / \mathrm{min}$. Plasma cholesterol was determined by the method of Levine \& Zak (1964).

\section{Aortic analysis}

At the end of 9 months, the pigeons were killed, the aortas were dissected quickly and the area of the aorta near the coeliac branch of the artery (where lesions always develop in the pigeon) (Lauper et al. 1975) was dissected out. These segments were weighed and made into three pools (from each group). Five birds from each group were used for the histologic studies, as described previously (Lauper et al. 1975).

Chemical analyses were carried out on three separate pools of aorta (each pool involving three to four birds) for a given age and breed. Total lipids from each pool of aorta were extracted with 20 vol. chloroform-methanol $(2: \mathrm{I}, \mathrm{v} / \mathrm{v})$, as described by Folch et al. (1957). Various lipids were separated by thin-layer chromatography on silica gel $G$ using a solvent system of heptane-isopropyl ether-acetic acid (65:40:4, by vol.), as described previously (Subbiah et al. 1976). In this solvent system, all the phospholipids remain at the origin. Bands corresponding to standards of free cholesterol and cholesterol esters were marked and removed into vials. The steryl ester fraction was saponified with I M-sodium hydroxide in ethanol (200 ml/l) (Subbiah et al. 1976). The sterol and fatty acid fractions were separated by extraction before and after acidification. The fatty acids were then methylated and quantified by gas-liquid chromatography as described previously (Subbiah et al. 1976). The sterol fraction was converted into its trimethylsilyl ethers and subjected to gas-liquid chromatography, as described previously for faecal sterols. Liver cholesterol content was measured by methods similar to that described previously for arterial sterols (Subbiah et al. 1976).

\section{RESULTS}

When compared with the control group, the dietary-restricted group had a decrease in weight of nearly $30 \%$ and had a decrease of $20 \%$ in the plasma cholesterol level during the 9 -month period (Table 1 ). The weight of the ad lib. group decreased by $15 \%$ from 3 months to 9 months of age.

The excretion of bile acids decreased significantly $(P<0.05)$, while the neutral sterols showed no difference (Table 2$)$. This resulted in a significant decrease $(P<0.01)$ in the excretion of total faecal steroids. Because the pigeon diet was cholesterol free, excretion 
Table 2. Faecal neutral sterol and bile acid excretion and liver cholesterol content in White Carneau pigeons subjected to dietary restriction

(Mean values with standard errors)

\begin{tabular}{|c|c|c|c|c|c|}
\hline \multirow[b]{2}{*}{ Group $\dagger$} & \multirow[b]{2}{*}{$\begin{array}{l}\text { No. of } \\
\text { birds }\end{array}$} & \multicolumn{3}{|c|}{ Cholesterol excretion (mg/kg per d) } & \multirow{2}{*}{$\begin{array}{c}\text { Liver } \\
\text { cholesterol } \\
(\mathrm{mg} / \mathrm{g})\end{array}$} \\
\hline & & Neutral sterols & Bile acids & $\begin{array}{l}\text { Total faecal } \\
\text { steroids }\end{array}$ & \\
\hline $\begin{array}{l}\text { Ad lib. } \\
\text { Dietary restriction }\end{array}$ & $\begin{array}{l}5 \\
5\end{array}$ & $\begin{array}{l}13 \cdot 6 \pm 2 \cdot 7 \\
13 \cdot 1 \pm 6 \cdot 2\end{array}$ & $\begin{array}{l}48 \cdot 6 \pm 7 \cdot 2 \\
14.9 \pm 4 \cdot 3^{*}\end{array}$ & $\begin{array}{l}61 \cdot 7 \pm 7 \cdot 5 \\
27 \cdot 9 \pm 4 \cdot 6 *\end{array}$ & $\begin{array}{l}2.4 \pm 0.2 \\
2 \cdot 0 \pm 0.3\end{array}$ \\
\hline
\end{tabular}

Statistically different from ad lib. group: $* P<0.05$; $^{* *} P<0.01$.

$\dagger$ For details, see p. 2.

Table 3. Cholesterol and cholesteryl ester content in aorta of White Carneau pigeons subjected to dietary restriction

(Mean values with standard errors)

\begin{tabular}{|c|c|c|c|c|}
\hline \multirow[b]{2}{*}{ Group $\dagger$} & \multirow{2}{*}{$\begin{array}{l}\text { No. of } \\
\text { birds }\end{array}$} & \multicolumn{3}{|c|}{ Aortic cholesterol (mg/g lipid-free dry wt) } \\
\hline & & Free & Fster & Total \\
\hline $\begin{array}{l}\text { Ad lib. } \\
\text { Dietary restriction }\end{array}$ & $\begin{array}{l}10 \\
10\end{array}$ & $\begin{array}{l}8.2 \pm 0.6 \\
5.4 \pm 0.8^{*}\end{array}$ & $\begin{array}{l}2 \cdot 9 \pm 0.4 \\
1 \cdot 9 \pm 0.3^{* *}\end{array}$ & $\begin{array}{r}\operatorname{Ir} \cdot 1 \pm 0.7 \\
7 \cdot 3 \pm 1 \cdot 1 *\end{array}$ \\
\hline
\end{tabular}

Statistically different from ad lib. group: $* P<0.01,{ }^{* *} P<0.02$.

† For details, see p. 2.

Table 4. Fatty acid composition of aortic cholesteryl esters of White Carneau pigeons subjected to dietary restrictions

(Mean values and standard errors)

\begin{tabular}{|c|c|c|c|c|c|c|c|c|c|}
\hline \multirow[b]{2}{*}{ Group $\dagger$} & \multirow{2}{*}{$\begin{array}{c}\text { No. of } \\
\text { birds }\end{array}$} & \multicolumn{8}{|c|}{ Fatty acid composition $(\mathrm{mmol} / \mathrm{mol}) \ddagger$} \\
\hline & & $14: 0$ & $16: 0$ & I6: I & I8:0 & $18: 1$ & $18: 2$ & $20: 4$ & Others \\
\hline Ad lib. & 10 & $\begin{array}{r}10.3 \\
\pm 0.5\end{array}$ & $\begin{array}{r}26.9 \\
\pm 2.1\end{array}$ & $\begin{array}{r}3.6 \\
\pm 2.1\end{array}$ & $\begin{array}{r}10.2 \\
\pm 0.3\end{array}$ & $\begin{array}{r}19.6 \\
\pm 0.4\end{array}$ & $\begin{array}{r}19 \cdot 7 \\
\pm 1 \cdot 2\end{array}$ & $\begin{array}{r}7.0 \\
+33\end{array}$ & $\begin{array}{r}9.6 \\
\pm 0.8\end{array}$ \\
\hline Dietary restriction & Io & $\begin{array}{r}4.5 \\
\pm 0.4\end{array}$ & $\begin{array}{r}38.4 \\
\pm 2.3\end{array}$ & $\begin{array}{r}6.6 \\
\pm 0.7\end{array}$ & $\begin{array}{r}13.5 \\
\pm 0.8\end{array}$ & $\begin{array}{r}16.0 \\
\pm I .8\end{array}$ & $\begin{array}{r}12.0 \\
\pm 0.7^{*}\end{array}$ & Trace & $\begin{array}{r}1.7 \\
\pm 0.6\end{array}$ \\
\hline
\end{tabular}

Significantly different from ad lib. group: $* P<0.0 \mathrm{I}$.

$\dagger$ For details, see p. 2.

$\$$ Values obtained from a mean of analysis of three pools.

represented the total endogenous cholesterol synthesis in the body. No difference was seen between the two groups in the cholesterol content of the liver.

The content of total cholesterol in the aorta of pigeons subjected to dietary restriction was significantly $(P<0.01)$ decreased in comparison with that of the control pigeons (Table 3). The major decrease in the cholesterol occurred in the free sterol fraction $(P<0.01)$. The decrease in cholesterol and cholesteryl ester fraction was confirmed by histologic studies with Oil Red O staining (Plate I). The main differences in the fatty acid composition of the steryl ester fraction were a complete lack of arachidonic acid in the dietary-restricted group and a reduction in the concentration (\%) of linoleic acid (Table 4 ). 


\section{DISCUSSION}

This study shows, for the first time, that dietary restriction started eariy in life can prevent the age-related accumulation of cholesterol in the aorta which occurs during spontaneous atherosclerosis in the White Carneau pigeon.

Studies by Barrows \& Kokkonen (1975) involving reduced energy intake and by Ross (1972) involving reduced protein levels during infancy have demonstrated an increase in the life-span of rats. Studies by Koletsky \& Puterman (1976, 1977) found that a low-energy diet decreased the incidence of atherosclerosis and hyperlipidemia and increased the life-span in genetically-obese rats. These beneficial effects may be due to their role in decreasing degenerative diseases like atherosclerosis. A previous study from our laboratory (Subbiah, 1977) reported a decreased aortic cholesterol content associated with the feeding of a lowprotein diet.

The present study shows that dietary restriction specifically decreased the content of both free and esterified cholesterol in the aorta, thus preventing or delaying one of the critical events in the pathogenesis of atherosclerosis. At I year of age, the coeliac bifurcation of the pigeon shows intimal proliferation with lipid droplets forming what could be termed a 'fatty streak'. Dietary restriction thus seems to prevent the evolution of the fatty streak in these pigeons. It remains to be seen whether the pigeons at the end of 3 years (continuing study) will eventually have lesser atherosclerosis. The plasma cholesterol levels after 9 months of dietary restriction decreased by $20 \%$. The excretion of total faecal steroids (equivalent to total endogenous cholesterol synthesis in these pigeons on the cholesterolfree grain diet) was significantly reduced after dietary restriction, indicating that body cholesterol synthesis is reduced. Whether the decreased content of cholesterol and cholesteryl esters noted in the aorta after dietary restriction is due to decreased synthesis by the aorta or to decreased movement of cholesterol from the plasma (via lipoproteins) remains to be investigated.

In any study of dietary restriction, attention has to be given to the effect that intervention has on other body factors, that is, growth and development. Apart from their decreased body-weight, the pigeons on dietary restriction showed no difference in body length, liver weight, fat content, and plasma albumin and glucose levels. The pigeons were active and had normal stools (M. T. R. Subbiah, unpublished results). It should be noted that the ad lib. group of pigeons showed a $15 \%$ decrease in weight from 3 months to 9 months of age. No explanation can be given at the present time. The present study is not intended to give the impression that aortic cholesterol accumulation and atherosclerosis should be modified at the expense of growth and development. Obviously, there is a range of dietary restriction in which the effect on body growth and development is minimal and in which the age-related arterial changes can be prevented. The present study suggests that age-related arterial changes leading to atherosclerosis can be prevented or at least delayed by intervention programmes started early in life and that nutritional intervention seems to be effective. Thus, dietary restriction and weight reduction could conceivably have beneficial effects in the development of degenerative diseases in man.

The authors are indebted to Miss Laurie K. Vongroven and Mr Curt Grabau for technical assistance in the handling of animals. The continued encouragement and interest of $\mathrm{Dr}$ B. A. Kottke is gratefully acknowledged. The work was supported in part by Grant HL186 Io from the National Heart and Lung Institute. 


\section{REFERENCES}

Armstrong, M. L., Warner, E. D. \& Connor, W. E. (1970). Circulation Res. 27, 59.

Barrows, C. H. Jr \& Kokkonen, G. (1975). Growth 39, 525.

Clarkson, T. B., Prichard, R. W., Netsky, M. G. \& Lofland, H. B. (1959). Arch. Path. 68, 143.

Folch, J., Lees, M. \& Sloane Stanley, G. H. (1957). J. biol. Chem. 226, 497.

Haust, M. D. (1971). Hum. Path. 2, 1.

Koletsky, S. \& Puterman, D. I. (1976). Proc. Soc. exp. Biol. Med. 151, 368.

Koletsky, S. \& Puterman, D. I. (1977). Exp. Mol. Fath. 26, 415.

Lauper, N. T., Unni, K. K., Kottke, B. A. \& Titus, J. L. (1975). Lab. Invest. 32, 536.

Levine, J. B. \& Zak, B. (1964). Clinica chim. Acta ro, $38 \mathrm{I}$.

Lofland, H. B. Jr, Moury, D. M., Hoffman, C. W. \& Clarkson, T. B. (I965). J. Lipid Res. 6, I 12.

Miettinen, T. A., Ahrens, E. H. Jr \& Grundy, S. M. (1965), J. Lipid Res. 6, 4 I I.

National Heart \& Lung Institute Task Force on Arteriosclerosis (1971). Arteriosclerosis, DHEW Publication no. 72-219 (NIH), vol. 2. Bethesda, Maryland: National Institutes of Health.

Ross, M. H. (1972). Am. J. clin. Nutr. $25,834$.

Spittell, D., Vongroven, L. K. \& Subbiah, M. T. R. (1976). Biochim. biophys. Acta 441, 32.

Strong, J. P. \& McGill, H. C. Jr (1969). J. Atheroscler. Res. 9, 25 I.

Subbiah, M. T. R. (1973). J. Lipid Res. 14, 692.

Subbiah, M. T. R. (1977). Nutr. Rep. int. 15, 223.

Subbiah, M. T. R. \& Connelly, P. W. (1976). Atherosclerosis 24, 509.

Subbiah, M. T. R., Tyler, N. E., Buscaglia, M. D. \& Marai, L. (1976). J. Lipid Res, 17, 78.

Subbiah, M. T. R., Unni, K. K., Kottke, B. A., Carlo, I. A. \& Dinh, D. M. (1976). Exp. Mol. Path. $24,287$.

Tucker, C. F., Catsulis, C., Strong, J. P. \& Eggen, D. A. (197 I). Am. J. Path. 65, 493.

\section{EXPLANATION OF PLATE}

Plate I

Sections from aorta of control (A) and dietary-restricted (B) White Carneau pigeons. Lumen is at the top. Note lack of dark staining near and around the luminal surface in the dietary-restricted pigeons. (Oil Red $O$ staining; $\times 600$ ). 

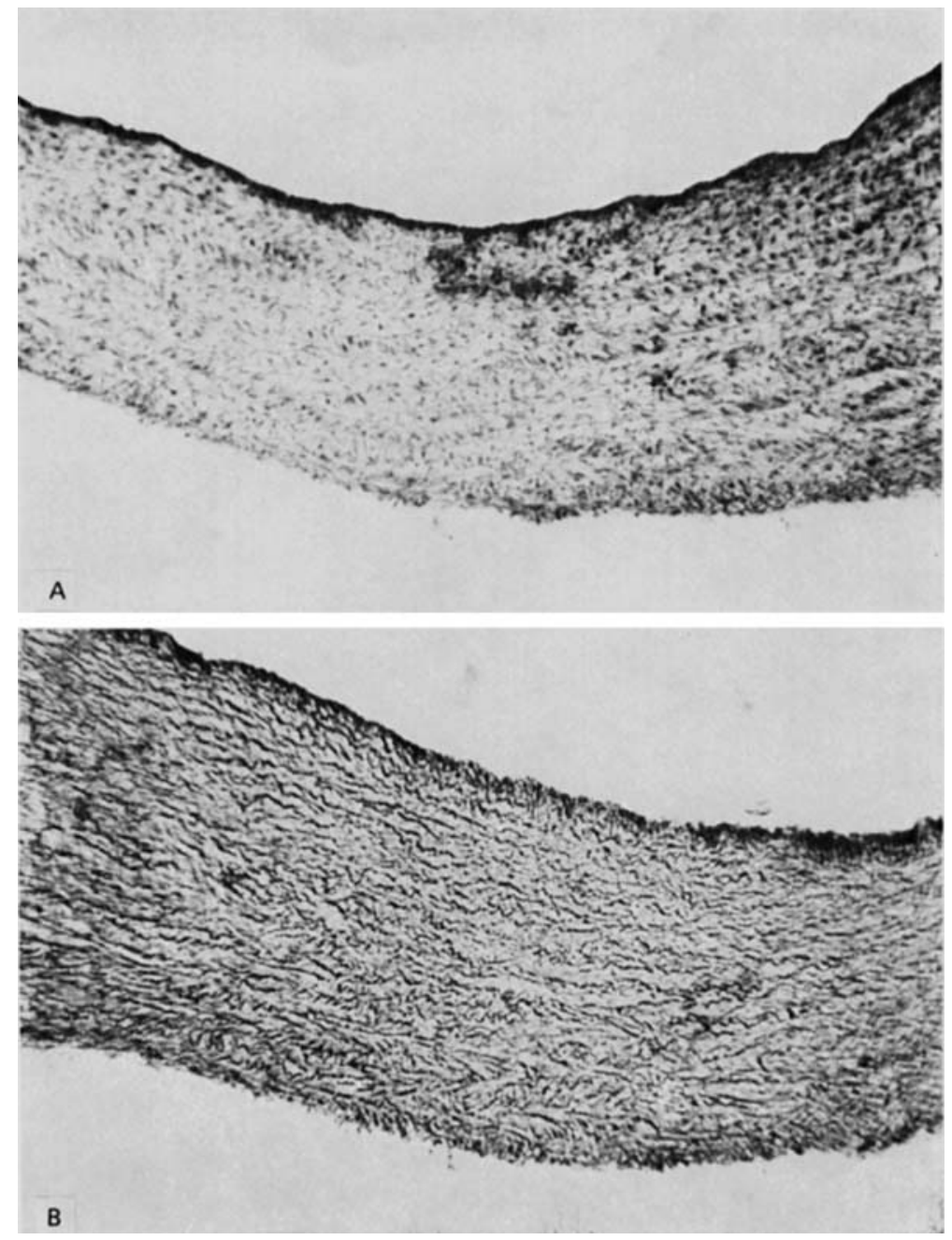